\title{
An Epidemiological Assessment of the Infectious forms of Intestinal Helminths in School Children from Chad
}

\author{
Hamit Mahamat Alio \\ Faculty of Human Health Sciences, \\ University of N'Djamena, P.O. Box 1117, N'Djamena, Chad \\ Faculty of Sciences, University of Yaoundé 1, P.O. Box 812 Yaoundé, Cameroon \\ E-mail: hamitalio@yahoo.fr \\ Abdelsalam Tidjani (Corresponding author) \\ Faculty of Human Health Sciences \\ University of N'Djamena, P.O. Box 1117, N'Djamena, Chad \\ National Centre of Nutrition and Food Technology of the Public Health Ministry \\ P.O. Box 440 N'Djamena, Chad \\ E-mail: abdelti@yahoo.fr \& abdelti@gmail.com
}

Brahim Boy Otchom
Faculty of Human Health Sciences
University of N'Djamena, P.O. Box 1117, N'Djamena, Chad

Mahamat Tahir Tidjani

Faculty of Human Health Sciences

University of N'Djamena, P.O. Box 1117, N’Djamena, Chad

Bilong Bilong Charles Felix

Faculty of Sciences, University of Yaoundé 1, P.O. Box 812 Yaoundé, Cameroon

E-mail: bilong_bilong@yahoo.com 
Received: August 2, 2013 Accepted: August 22, 2013

doi:10.5296/jbls.v4i2.4258

URL: http://dx.doi.org/10.5296/jbls.v4i2.4258

\begin{abstract}
Intestinal helminths constitute the primary cause of illnesses in pre and school age children in the less developed countries. Their importance has been disregarded for a long time because of their insidious and chronic nature. In order to assess the prevalence rate of intestinal helminths in Chadian children, a survey of intestinal worms was carried out from March 2010 to February 2011 in two ecological zones (Sahelian and Sudanian zones) in the Republic of Chad. 1002 children (541 boys and 461 girls) aged from 6 to 17 years were enrolled in our investigation. The coprological analysis carried out in this study included macroscopic examination, direct microscopic examination and two concentration techniques (the Kato method and the formalin-ether concentration technique). The results showed highly significant differences in the prevalence of intestinal helminths between the two ecological zones, the prevalence being generally higher in the Sudanian zone than in the Sahelian one. Among all the helminths identified in the two zones, Ascaris lumbricoides was the most common, followed by Hymenolepis nana. A regular deworming and improvement of the hygienic conditions in these zones could go a long way to prevent intestinal worm infections. The findings of the present study urgently call for an improvement in environmental hygiene, the sanitary education of the populations and the creation of a national program for the fight against intestinal helminths in Chad.
\end{abstract}

Keywords: Epidemiology, Intestinal helminths, Children, School environment, Sudanian zone, Sahelian zone, Chad.

\title{
1. Introduction
}

Infections by intestinal helminths are the leading cause of illnesses among young people worldwide (OMS, 2004). High prevalence was observed in developing countries in tropical regions where poor sanitation, poor climatic conditions and low socio-economic status causes these parasites to pose a serious public health problem (Menan et al., 1997; Perez, 2000; Savioli et al., 2002; Tchuem Tchuenté, 2011 \& 2012). Consequently they induce diseases that should neither be neglected nor put in the background (Menan et al., 1997). The importance of the problem has long been neglected because these diseases are responsible for infant mortality due to their insidious and chronic nature (Tchuem Tchuenté, 2011). According to OMS (2001) and Brooker et al. (2002a), 2 billion people worldwide were infected with schistosomasis and soil-transmitted helminths (STH) with 300 million being severely affected and an increasingly high prevalence people living in less developed countries. It is often among preschool (2-5 years) and school aged children that infection rates are highest or $\geq 35 \%$ (Edwin, 2004). Using a probabilistic model to predict the prevalence and the number of children with helminthiasis in Africa, Tchuem Tchuente (2011) estimated that more than 30.7 million school children are infected with Ascaris lumbricoides, 36.5 million with Trichuris trichiura and 50 million with hookworms. Children are particularly exposed to helminths for behavioral, hygienic and 


\section{Macrothink

recreational reasons. 400 million school age infected subjects undergo frequent physical and mental suffering due to anemia, which results in a lack of attention, inability to assimilate knowledge and contributes to absenteeism and school dropouts (Drake et al., 2000; Dreyfuss et al., 2000; Stephenson et al., 2000; Hall et al., 2001; WHO, 2002; Hotez et al., 2004; OMS, 2004). In Africa, the species such as Schistosoma mansoni, Ankylostoma sp., T. trichiura and A. lumbricoides respectively affect 25 million, 239 million, 233 million and 320 million children (Bundy et al., 1997; Van der Werf, 2003). Intestinal worms are responsible for a decreased immunity of children towards malaria, which further increases the anemia caused by hookworms (OMS, 2005). In these subjects, intestinal helminths are the principal isolated leading cause of diseases and represent up to $12 \%$ of the total burden nosology (UNICEF, 2007). Morbidity due to schistosomiasis and STH is enormous in tropical countries (Savioli et al., 2002).

In Chad, very little studies have been done on intestinal parasites. According to Brooker et al. (2002b), 32.7\% of Chad's rural population is infected with hookworm; Kostoingue et al. (2002) found that $57.7 \%$ of children harbor intestinal parasites in the city of N'Djamena. Recent studies showed that $60 \%$ of nomadic children in Chad are carriers of at least one intestinal parasite (Bechir et al., 2011) while Hamit et al. (2008) reported that $51 \%$ of the inhabitants of N'Djamena city are bearers of at least one intestinal parasites.

Within this context, the present study aims at determining the prevalence of intestinal helminths among chadian children aged from 6 to 17 years. Epidemiological data of this work will serve on the one hand as an advocacy tools for better personal and collective hygiene, a prerequisite in the fight against intestinal helminths and, on the other hand, will enable the implementation of a national program to fight against these parasites.

\section{Materials and Methods}

\subsection{Study Area}

Chad is a Sahelian country and land locked country in Central Africa with no coastline (Figure 1); it covers an area of $1,284,000 \mathrm{~km}^{2}$ with an estimated population of $11,679,974$ inhabitants (INSEED/RGPH2, 2010). 


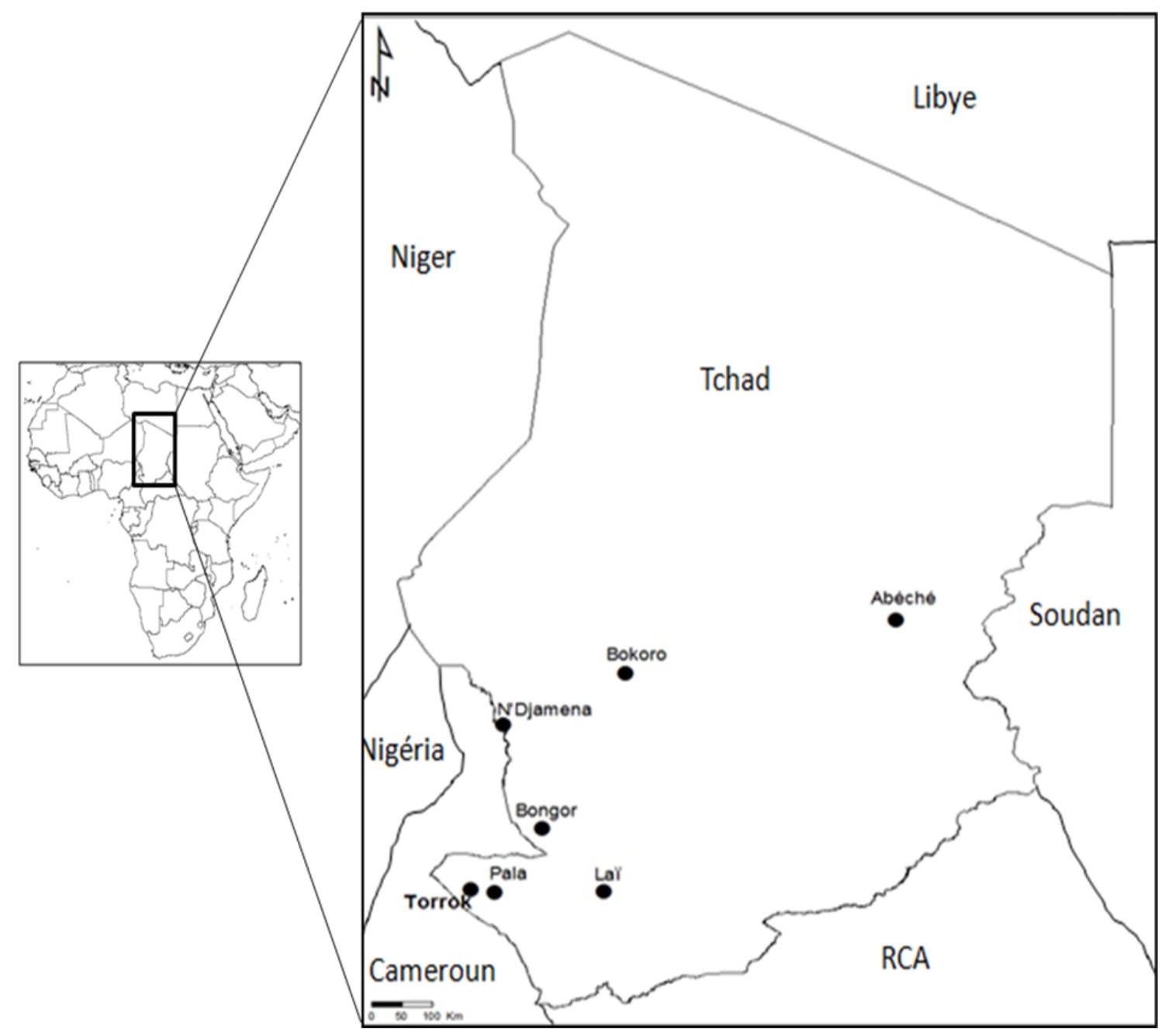

Figure1. Location of Chad and presentation of study sites (CNAR, 2012 amended)

With a growth rate of $3.1 \%$ in 2010 , this population is characterized by an uneven distribution on the national territory, abundant youth, a high concentration of people in rural areas, a high ethnical diversity (256 tribes), many religions (Islam, Christianity, traditional), and a 52\% representation of women (INSEED/RGPH2, 2010). Since 2003, the recurrent crisis in Darfur has forced more than 200,000 Sudanese to flee to Chad, in addition, tens of thousands of people were displaced within the country. On the economic front, Chad remains a very poor country despite the exploitation of oil in Doba (South) and in Chari-Baguirmi (Center) that has a refinery. The national health system is inefficient mainly because of the lack of qualified human resources, health facilities and medical equipment (OMS, 2010). Chad is divided into six ecological zones: Saharan, Sahel-saharan, Sahelian, Sudano-sahelian, Sudanian and Guinean (CNAR, 1998). This study was conducted in the Sahelian (Abeche, N'Djamena and Bokoro) and the Sudanian (Bongor, Pala, Torrok and Lai) zones (Figure 1). N'Djamena, the political capital of Chad, has a sahelian climate characterized by two seasons: a rainy season (June to September) and a dry season (October to May). Many of its neighborhoods are flooded during the rainy season. It is the most populated city in the country (Adibord, 1998). The 
climate in Abeche and Bokoro is also sahelian; Bokoro has the same periods of rainy and dry seasons as N'Djamena; even Abeche located in the mountains of Ouaddaï has a short rainy season from August to September. Bongor, Pala, Torrok, and Lai belong to the southern region of the country which has a tropical climate with three distinct seasons: a hot season from March to July, a rainy season from August to October and a cold season from November to February of the following year (DREM, 2013). Geographical and climatic characteristics of the study sites are presented in Table 1.

Table 1. Geographic and climatic characteristics of the study sites

\begin{tabular}{|c|c|c|c|c|c|}
\hline City & $\begin{array}{c}\text { Population } \\
\text { (inhabitants/City) }\end{array}$ & $\begin{array}{l}\text { Rainfall } \\
(\mathrm{mm})\end{array}$ & Longitude $\operatorname{East}\left({ }^{0}\right)$ & $\begin{array}{l}\text { Latitude } \\
\operatorname{North}\left({ }^{0}\right)\end{array}$ & $\begin{array}{c}\text { Elevation } \\
\text { (m) }\end{array}$ \\
\hline Abeche & 138684 & 100 to 400 & $20^{\circ} 85^{\prime}$ & $13^{0} 85^{\prime}$ & 545 \\
\hline Bokoro & 114050 & 300 to 700 & $17^{0} \quad 05^{\prime}$ & $12^{0} \quad 33^{\prime}$ & 300 \\
\hline Bongor & 69787 & 500 to 1300 & $15^{0} \quad 40^{\prime}$ & $10^{0} \quad 28^{\prime}$ & 320 \\
\hline Lai & 94695 & 700 to 1300 & $16^{0} 30^{\prime}$ & $9^{0} \quad 40^{\prime}$ & 358 \\
\hline N'Djamena & 951418 & 500 to 700 & $15^{0} \quad 03^{\prime}$ & $12^{0} \quad 13^{\prime}$ & 294 \\
\hline Pala & 108374 & 500 to 1200 & $14^{0} 92^{\prime}$ & $37^{\prime}$ & 454 \\
\hline Torrok & 49981 & 500 to 1200 & $15^{0} 02^{\prime}$ & $67^{\prime}$ & 355 \\
\hline
\end{tabular}

Source: DREM (2013) and INSEED/RGPH2 (2010)

\subsection{Population under Study}

This work is a cross-sectional and prospective study that is focused on 1002 children of male and female genders; primary school children aged from 6 to17 years constituted the sampled population, and were randomly selected from 10 schools in 7 cities of Chad from March 2010 to February 2011 (Table 2).

Table 2. Sampling period

\begin{tabular}{|c|c|c|}
\hline Cities & Schools & Sampling period \\
\hline \multirow{3}{*}{ N'Djamena } & Darhira & \multirow{3}{*}{22 to 31 March 2010} \\
\hline & Daralsalam & \\
\hline & Mandjafa & \\
\hline \multirow[t]{2}{*}{ Abeche } & Sultan Mahamat Ourada & \multirow[t]{2}{*}{20 to 27 April 2010} \\
\hline & Association of catholic sisters & \\
\hline Pala & Centre A & 18-19 January 2011 \\
\hline Torrok & Centre & 20-21 January 2011 \\
\hline Laï & Centre A & 22-23 January 2011 \\
\hline Bongor & Centre A & 24-25 January 2010 \\
\hline Bokoro & Centre A & 2-3 February 2011 \\
\hline
\end{tabular}

The size of the sample was determined by the cluster sampling technique (Fleiss, 1981; Spiegel, 1989) using the following formula: $n=\frac{P(1-P) z^{2}}{i^{2}}$ 
$\mathrm{P}=$ prevalence of the latest study $(37.52 \%)$ in the region of southern Chad (Brooker et al., $2002 b), n=$ sample size, $Z=$ is a given value of 1.96 , if the probability limit $\propto=0.05, n>30$; $i$ is error in percentage read in confidence limit table $=0.03$.

\subsection{Preparatory Activities for the Investigation}

A week before the study was carried out in each of the selected schools, a preliminary visit was carried out with the objective of assessing the level of sanitation on the one hand, and to sensitize pupils, teachers and other stake holders on the importance and necessity of the study as well as to seek their massive participation on the other hand.

A Socio-economic and health questionnaire developed on a survey form to collect information on the identity of the pupils, their habitat and lifestyle, was presented to the learner who agreed to participate in our investigation. This survey identified the general and food hygiene problems of each child.

Sampling collection was done in the morning. During the process, pupil that validated the age criterion were randomly selected; each child was then given a code number. Each Petri dish contained 3 to 5 drops of formalin 10\%; selected pupils were then sent to the toilets to fill their Petri dish with feces. Collected feces were transported to the laboratory for immediate examination.

\subsection{Methodology}

In the laboratory, 4 standard methods were used to evaluate the helminth load in each stool sampled; the 4 methods included a macroscopic examination, a direct microscopic examination, the Kato method and the formalin-ether concentration technique.

The Kato method is an approach used to estimate the helminthic load in a sample of prepared stool; the outline procedure of this method involves several stages. First, a small amount of fecal matter was placed on a hard surface; a sieve or screen was then pressed on top of the feces to it. The filtered part of the feces (on the upper surface of the screen) was scrapped using a spatula; the scraped feces collected was then transferred in the hole of the template until it is completely filled (Odongo-Aginya et al., 2007). The template was then removed carefully. The fecal material was covered with a cellophane strip which is initially soaked in glycerol solution for at least 24 hours. The microscopic slide was inverted and firmly pressed on the fecal sample against the cellophane strip on a smooth surface like tile such that the fecal material was evenly spread. Clarification was ensured by glycerol and the set up was kept for a couple of minutes. The smear was then examined systematically, and eggs of each helminth species were recorded. Macroscopic observations were made at magnifications of 100x and 400x to better appreciate the contrast of the different elements. The number of eggs obtained was multiplied by 24 because the template used has holes of diameter $6 \mathrm{~mm}$ and a thickness of $1.5 \mathrm{~mm}$ and stool weight of $41.5 \mathrm{mg}$ (Katz, 1972; OMS, 1983; OMS, 1993). For the formalin-ether concentration technique, a small stick was used to introduce a small amount of fecal matter in the test tubes initially containing $10 \mathrm{ml}$ of $10 \%$ formalin. The test tube was stirred and agitated vigorously such that a homogenous suspension of fecal matter was obtained. The homogenous suspension 
was then passed through a 2-layered fine-mesh wire sieve directly into a centrifugation tube, formalin was added to the centrifuge tube to raise the volume of the homogenous suspension to $10 \mathrm{ml} .0 .3 \mathrm{ml}$ of ether was then added and homogenized for 10 seconds. The suspension was centrifuged for 2-3 minutes at 400-500g. After the process of centrifugation, 4 different layers were obtained as follows: (a) a layer of ether at the surface (top), (b) a layer of fatty debris adhered on the walls of centrifugation tubes, (c) a layer of formalin and finally (d) a layer of sediments at the bottom. The 3 upper layers were carefully decanted living only the sediments in the tube; the sediments were mixed with some physiological water and placed on macroscopic slides for examination. Slides were observed at 100x and 400x to better appreciate the contrast of elements (OMS, 1993). Data collected were analyzed using the EPI INFO 6.0 software. The effect of age and sex on parasite hostage, global and specific prevalence and parasitic association were particularly studied. The 1002 randomly selected pupils in our sample were grouped according to gender and 3 age groups which are: 6-9, 10-14 and $15-17$ years old.

\section{Results}

This study reveals that out of the 1002 pupils sampled, $572(52.1 \%)$ had intestinal helminths, boys having a higher percentage (63.2\%) compared to $49.8 \%$ infection in girls. In general, boys more often harbour $(\mathrm{P}<0.05)$ parasites than girls $\left(\chi^{2}=18,04\right.$, ddl=1, Table 3$)$.

Table 3. Global percentage in both sexes harboring at least one parasite species

\begin{tabular}{|l|c|c|c|}
\hline Sex & $\mathrm{n}$ & $\mathrm{n}$ & $(\%)$ \\
\hline Male & 541 & 342 & 63.2 \\
\hline Female & 461 & 230 & 49.9 \\
\hline Total & 1002 & 572 & 57.1 \\
\hline
\end{tabular}

Legend: $\mathrm{n}=$ number of children examined; $\mathrm{n}^{\prime}=$ number of pupils harboring at least one helminth species; $(\%)=$ percentage of infection.

The prevalence of helminths was higher among children in urban schools in the Sudanian zone as compared to schools in Sahelian zone (Table 4).

Table 4. Numbers and proportions of children bearing at least one helminth species per school and Chadian town of both ecological zones

\begin{tabular}{|c|c|c|c|c|c|c|c|c|c|c|c|}
\hline \multirow[t]{2}{*}{ Ecological zones } & \multirow[t]{2}{*}{ Cities } & \multicolumn{4}{|c|}{ Schools } & \multicolumn{3}{|c|}{ Subtotal by city } & \multicolumn{3}{|c|}{$\begin{array}{l}\text { Subtotal by ecological } \\
\text { zone }\end{array}$} \\
\hline & & & $\mathrm{n}$ & n' & $(\%)$ & $\mathrm{n}$ & $\mathrm{n}^{\prime}$ & $(\%)$ & $\mathrm{n}$ & n' & $(\%)$ \\
\hline \multirow[t]{4}{*}{ Sahelian Zone } & \multirow[b]{2}{*}{ Abeche } & ASC & 101 & 20 & 19.8 & \multirow[t]{2}{*}{210} & \multirow[t]{2}{*}{81} & \multirow[t]{2}{*}{38.6} & \multirow[t]{4}{*}{588} & \multirow[t]{4}{*}{289} & \multirow[t]{4}{*}{49.1} \\
\hline & & SMO & 109 & 61 & 56 & & & & & & \\
\hline & Bokoro & BokA & 109 & 76 & 69.7 & 109 & 76 & 69.7 & & & \\
\hline & & Dah & 100 & 54 & 54 & & & & & & \\
\hline
\end{tabular}




\begin{tabular}{|c|c|c|c|c|c|c|c|c|c|c|c|}
\hline & \multirow[t]{2}{*}{ N'Djamena } & Dar & 105 & 55 & 52.3 & \multirow[t]{2}{*}{269} & \multirow[t]{2}{*}{132} & \multirow[t]{2}{*}{49.1} & & & \\
\hline & & Man & 64 & 23 & 36 & & & & & & \\
\hline Sudanian Zone & Bongor & BonA & 102 & 73 & 71.5 & 102 & 73 & 71.5 & 414 & 283 & 68.4 \\
\hline & Laï & $\mathrm{La} A$ & 109 & 71 & 65.1 & 109 & 71 & 65.1 & & & \\
\hline & Pala & $\mathrm{Pa} \mathrm{A}$ & 102 & 70 & 68.6 & 102 & 70 & 68.6 & & & \\
\hline & Torrok & Tor & 101 & 69 & 68.3 & 101 & 69 & 68.3 & & & \\
\hline
\end{tabular}

Legend: $\mathrm{n}=$ number of children examined; $\mathrm{n}^{\prime}=$ number of pupils bearing at least one helminth species; $(\%)=$ percentage of infection; SMO = Sultan Mahamat Ourada school; ASC = Association of Catholic Sisters School; BokA = Bokoro School Centre A; Dah = Darhira School; Dar = Daralsalam School; Man = Mandjafa School; BonA = Bongor Centre A School; LaA = Centre A Lai School; PaA = Pala Centre A School; Tor = School Torrok Centre.

Intrazonal analysis revealed variations in infection rate within cities in the Sahelian zone at $\mathrm{P}<$ 0.05 and $\chi^{2}=27.87$, ddl $=2$, contrarily to the Sudanian zone where the differences in infection rate were not significant $\left(\mathrm{P}>0.05, \chi^{2}=1.01, \mathrm{ddl}=3\right)$.

In this study, 8 species of parasites were identified, among which were 4 nematodes, 3 tapeworms and 1 trematode. Ascaris lumbricoides (33.7\%) and Hymenolepis nana (20.5\%) were the most common helminthes in Chad; they were followed by hookworms and Strongyloides stercoralis with prevalence of $12.5 \%$ and $12.4 \%$ respectively. Prevalence rate of the other parasites identified were: T. solium (0.7\%), T. trichiura $(2.6 \%)$, S. mansoni $(3.4 \%)$ and T. saginata $(5.7 \%)$ (Table 5).

Table 5. Prevalence of helminth species in both sexes and the general population

\begin{tabular}{|c|c|c|c|c|c|c|c|}
\hline \multirow{2}{*}{\multicolumn{2}{c|}{ Parasites }} & \multicolumn{2}{c|}{ Boys $(\mathrm{n}=541)$} & \multicolumn{2}{c|}{ Girls $(\mathrm{n}=461)$} & \multicolumn{2}{c|}{ Total (N =1002) } \\
\cline { 2 - 8 } & A. lumbricoides & 201 & $37.2^{*}$ & 137 & $29.7^{*}$ & 338 & $33.7^{*}$ \\
\cline { 2 - 8 } & Ankylostomes & 78 & $14.4^{*}$ & 47 & $10.2^{*}$ & 125 & 12.5 \\
\cline { 2 - 8 } & T. trichiura & 11 & 2 & 15 & 3.3 & 26 & 2.6 \\
\cline { 2 - 8 } & S. stercoralis & 80 & $14.8^{*}$ & 44 & $9.5^{*}$ & 124 & 12.4 \\
\hline \multirow{4}{*}{ Cestoda } & T. solium & 3 & 0.6 & 4 & 0.9 & 7 & 0.7 \\
\cline { 2 - 8 } & T. saginata & 48 & $8.9^{*}$ & 9 & $2^{*}$ & 57 & 5.7 \\
\cline { 2 - 8 } & H. nana & 108 & 20 & 97 & 21 & 205 & $20.5^{*}$ \\
\hline Trematoda & S. mansoni & 15 & 2.8 & 19 & 4.1 & 34 & 3.4 \\
\hline
\end{tabular}

Legend: $n=$ number of children examined as a function of sex; $n^{\prime}=$ number of pupils carrying the helminth species; $(\%)=$ percentage of infection; $\mathrm{N}=$ total number of children sampling; $*=$ the highest percentage.

Specific parasite indices were different $(\mathrm{P}<0.05)$ in both sexes (Table 5) for A. lumbricoides, hookworms, S. stercoralis and T. saginata, the prevalence being higher in males than in females ( $\chi^{2}$ values respectively equal to $6.16,4.06,6.31$ and 22.2 ). Two species (T. solium and 
S. mansoni) were absent in the Sahelian zone (Table 6). Hookworms were only diagnosed in the town of N'Djamena while T. trichiura and S. stercoralis were not found in Bokoro.

Table 6. Number of children and prevalence rate of each parasite species as a function of the city and the ecological zone studies

\begin{tabular}{|c|c|c|c|c|c|c|c|c|}
\hline Cities (n) & $\mathrm{AL}(\%)$ & $\mathrm{AN}(\%)$ & $\mathrm{TT}(\%)$ & SS (\%) & $\mathrm{HN}(\%)$ & $\mathrm{TA}(\%)$ & TO (\%) & SM (\%) \\
\hline $\mathrm{Ab}(210)$ & $33(15.7)$ & 0 & $3(1.4)$ & $2(1)$ & $36(17.1)$ & 21(10) & 0 & 0 \\
\hline Bok(109) & $45(41.2)$ & 0 & 0 & 0 & $40(36.7)$ & $18(16.5)$ & 0 & 0 \\
\hline $\mathrm{Nd}(269)$ & $104(3.6)$ & $5(1.8)$ & $1(0.3)$ & $2(0.7)$ & $63(23.4)$ & $13(4.8)$ & 0 & 0 \\
\hline $\begin{array}{l}\text { Subtotal (Sahelian } \\
\text { zone })(n=588)\end{array}$ & $182(31)$ & $5(0.8)$ & $4(0.6)$ & $4(0.6)$ & $139(23.6)$ & $52(8.8)$ & 0 & 0 \\
\hline Bon(102) & $34(33.3)$ & $33(32.3)$ & 0 & $27(26.4)$ & $35(34.3)$ & 0 & 0 & $1(1)$ \\
\hline $\mathrm{La}(109)$ & $48(44)$ & $22(20.1)$ & $1(1)$ & $32(29.3)$ & $16(14.6)$ & $3(2.7)$ & $1(1)$ & 0 \\
\hline $\operatorname{Pal}(102)$ & $46(45.1)$ & $24(23.5)$ & 0 & $29(28.4)$ & $9(8.8)$ & $2(2)$ & 0 & $17(16.6)$ \\
\hline Tor(101) & $28(27.7)$ & $41(40.6)$ & $21(20.8)$ & $32(31.6)$ & $6(5.9)$ & 0 & $6(5.9)$ & $16(15.8)$ \\
\hline $\begin{array}{l}\text { Subtotal (Sudanian } \\
\text { zone }) \quad(n=414)\end{array}$ & $156(37.6)$ & $120(29)$ & $22(5.3)$ & $120(29)$ & $66(16)$ & $5(1.2)$ & $7(1.7)$ & $34(8.2)$ \\
\hline
\end{tabular}

Legend: $\mathrm{n}=$ number of children examined; $(\%)=$ percentage of infection; $\mathrm{Ab}=\mathrm{Abeche}$; Bok $=$ Bokoro; Nd =N'Djamena; Bon = Bongor; La = Lai; Pal = Pala; Tor = Torrok; $\mathrm{AL}=$ A. lumbricoides; $\mathrm{AN}=$ hookworm; TT = T. trichiura $; \mathrm{SS}=$ S. stercoralis $; \mathrm{HN}=H$. nana $; \mathrm{TA}=$ T. saginata $; \mathrm{TO}=$ T. solium $; \mathrm{SM}=$ S. mansoni.

The results also indicated that the most infected age group was "10-14", all the 8 parasites were diagnosed in this age group within which the infection rates were different among parasite species (Table 7).

Table 7. Prevalence rate of each parasite species as a function of the age group

\begin{tabular}{|c|c|c|c|c|c|c|c|}
\hline \multirow{3}{*}{\multicolumn{2}{|c|}{ Parasites }} & \multicolumn{6}{|c|}{ Age groups (years) } \\
\hline & & \multicolumn{2}{|c|}{ "6-9" (n=310) } & \multicolumn{2}{|c|}{ "10-14" (n=612) } & \multicolumn{2}{|c|}{$" 15-17 "(n=80)$} \\
\hline & & n' & $(\%)$ & n' & $(\%)$ & n' & $(\%)$ \\
\hline \multirow{4}{*}{ Nematoda } & A. lumbricoides* & 89 & 28.7 & 216 & 35.3 & 33 & 41.3 \\
\hline & hookworm * & 25 & 8.1 & 93 & 15.2 & 7 & 8.8 \\
\hline & T. trichiura* & 2 & 0.6 & 23 & 3.8 & 1 & 1.3 \\
\hline & S. stercoralis* & 18 & 5.8 & 103 & 16.8 & 3 & 3.8 \\
\hline \multirow{3}{*}{ Cestoda } & T. solium & 0 & 0 & 7 & 1.1 & 0 & 0 \\
\hline & T. saginata* & 0 & 0 & 35 & 5.7 & 22 & 27.5 \\
\hline & H. nana* & 143 & 46.1 & 59 & 9.6 & 3 & 3.8 \\
\hline Trematoda & S. mansoni* & 1 & 0.3 & 31 & 5.1 & 2 & 2.5 \\
\hline
\end{tabular}

Legend: $\mathrm{n}=$ number of students examined, $\mathrm{n}^{\prime}=$ number of students carrying the helminth species, $(\%)=$ percentage of infestation, infestation $*=$ prevalence rate different between the three age classes rate.

Monoparasitism, and polyparasitism (up to 4 species) were observed in this study; the 


\section{Ml Macrothink}

Journal of Biology and Life Science

ISSN 2157-6076

2013, Vol. 4, No. 2

percentage of polyparasitism cases decreased significantly while the number of parasites species in the association increased $\left(\mathrm{P}<0.05, \mathrm{ddl}=3 ; \chi^{2}=454.01\right.$; Table 8$)$.

Table 8. Distribution of infected children according to parasite associations

\begin{tabular}{|c|c|c|c|}
\hline Type of parasitism & Parasite species & n' & $(\%)$ \\
\hline \multirow{8}{*}{ Monospecific } & $\mathrm{AL}$ & 144 & 14.4 \\
\hline & $\mathrm{AN}$ & 5 & 0.5 \\
\hline & TT & 4 & 0.4 \\
\hline & SS & 13 & 1.3 \\
\hline & $\mathrm{HN}$ & 84 & 8.4 \\
\hline & TA & 33 & 3.3 \\
\hline & TO & 6 & 0.6 \\
\hline & SM & 1 & 0.1 \\
\hline & Subtotal & 290 & 28.9 \\
\hline \multirow{15}{*}{ Bispecific } & AL-HN & 90 & 9 \\
\hline & AL-AN & 15 & 1.5 \\
\hline & AL-SM & 4 & 0.4 \\
\hline & AL-TA & 22 & 2.2 \\
\hline & AL-TO & 1 & 0.1 \\
\hline & AL-TT & 9 & 0.9 \\
\hline & AL-SS & 21 & 2.1 \\
\hline & AN-HN & 7 & 0.7 \\
\hline & AN-SS & 41 & 4.1 \\
\hline & AN-SM & 10 & 1 \\
\hline & SS-HN & 2 & 0.2 \\
\hline & SS-SM & 1 & 0.1 \\
\hline & SS-TT & 1 & 0.1 \\
\hline & HN-TT & 1 & 0.1 \\
\hline & Subtotal & 225 & 22.5 \\
\hline \multirow{15}{*}{ Trispecific } & AL-AN-TT & 1 & 0.1 \\
\hline & AL-AN-HN & 2 & 0.2 \\
\hline & AL-AN-SS & 12 & 1.2 \\
\hline & AL-AN-SM & 2 & 0.2 \\
\hline & AL-TA-TT & 1 & 0.1 \\
\hline & AL-TA-SS & 1 & 0.1 \\
\hline & AL-SS-HN & 1 & 0.1 \\
\hline & AL-SS-TT & 2 & 0.2 \\
\hline & AL-SS-SM & 4 & 0.4 \\
\hline & AL-TT-SM & 1 & 0.1 \\
\hline & AN-SS-TT & 3 & 0.3 \\
\hline & AN-SS-SM & 6 & 0.6 \\
\hline & AN-SS-HN & 14 & 1.4 \\
\hline & AN-SM-HN & 2 & 0.2 \\
\hline & Subtotal & 52 & 5.2 \\
\hline \multirow{5}{*}{ Quadrispecific } & AL-AN-HN-SS & 1 & 0.1 \\
\hline & AL-AN-HN-TT & 1 & 0.1 \\
\hline & AL-AN-SM-SS & 1 & 0.1 \\
\hline & AL-SM-TT-AN & 2 & 0.2 \\
\hline & Subtotal & 5 & 0.5 \\
\hline
\end{tabular}


Legend: $\mathrm{n}$ '= number of pupils carrying the helminth species; $(\%)=$ percentage of infection; $\mathrm{AL}=A$. lumbricoides; $\mathrm{AN}=$ hookworm; $\mathrm{TT}=$ T. trichiura $; \mathrm{SS}=S$. stercoralis $; \mathrm{HN}=H$. nana $; \mathrm{TA}=T$. saginata $; \mathrm{TO}=T$. solium $; \mathrm{SM}=$ S. mansoni.

A. lumbricoides was the most frequent parasite species found in these associations; it was diagnosed in 194 children who were enrolled in the study. It was followed by H. nana (121 children) and hookworms (120 children), while T. solium was found in association with $A$. lumbricoides only once.

Chadians use water from diverse sources like wells, boreholes or SNE (National Society of Water) for cooking (Table 9).The results revealed a direct relationship between the intestinal parasite infection rate and the source of water supply. Percentage of infection was low (35.5\%) among children using water supplied by SNE, but high (up 88.2\%) for children relying exclusively on well water. About $89.4 \%$ chadian households stored drinking water in clay pot which is half buried in the ground, with a poor lid; intestinal worms were mostly acquired by consuming water stored in canaries and drums $\left(\mathrm{P}<0.05, \chi^{2}=5.68\right.$ and $\left.\mathrm{ddl}=1\right) .66 .6 \%$ of the children sampled indicated that they had a water point close to their homes against $33.4 \%$ who did not; however, the proportion of hosting at least one pathogenic species was higher $(\mathrm{P}<0.05$, $\left.\chi^{2}=39,13\right)$ in the first group.

Out of all questionnaires filled, $99.5 \%$ children did not wash their hands with soap before meals; among them, $57.1 \%$ bore intestinal parasites; in the remaining $(0.5 \%), 60 \%$ (pupils) hosted intestinal parasites. Children who wore open shoes $(40.7 \%)$ presented an infestation percentage of $70.3 \%$, different $\left(\mathrm{P}<0.05, \chi^{2}=49.38\right)$ from $48 \%$ for those who wore closed shoes. Children that lived in household alongside domestic animals (like cows, sheep, dogs, pigs, ducks) hosted more often (66.9\%) intestinal worms compared to $(47.5 \%)$, the infection rate of those who had no domestic animals in their homes $\left(\mathrm{P}<0.05, \chi^{2}=38.2\right.$, Table 9$)$.

Table 9. Infection rate by considering the water source, wearing shoes or not and the presence or absence of domestic animals in households

\begin{tabular}{|l|c|c|c|c|}
\hline \multicolumn{2}{|c|}{ Water supply source } & $\mathrm{n}$ & $\mathrm{n}$ & $(\%)$ \\
\hline \multirow{4}{*}{ Cooking water } & SNE & 211 & 75 & 35.5 \\
\cline { 2 - 5 } & SNE and manual pump drilling & 57 & 23 & 40.3 \\
\cline { 2 - 5 } & Manual pumps drilling & 717 & 459 & 64 \\
\cline { 2 - 5 } & Wells & 17 & 15 & 88.2 \\
\hline \multirow{2}{*}{ Mode of water storage at home } & Canaris & 896 & 500 & 55.8 \\
\cline { 2 - 5 } & Canaris and drums & 106 & 72 & 67.9 \\
\hline Presence of a water point close to the concession & Yes & 335 & 145 & 43.3 \\
\cline { 2 - 5 } & No & 667 & 427 & 64 \\
\hline
\end{tabular}




\begin{tabular}{|l|c|r|r|r|}
\hline \multirow{2}{*}{ Washing hands with soap before meals } & No & 997 & 569 & 57.1 \\
\cline { 2 - 5 } & Yes & 5 & 3 & 60 \\
\hline wearing of shoes & closed & 594 & 285 & 48 \\
\cline { 2 - 5 } & Open & 408 & 287 & 70.3 \\
\hline Pets at home & Absence & 507 & 241 & 47.5 \\
\cline { 2 - 5 } & Presence & 495 & 331 & 66.9 \\
\hline
\end{tabular}

Legend: $\mathrm{n}=$ number of children examined; $\mathrm{n}^{\prime}=$ number of pupils carrying the helminth species; $(\%)=$ percentage of infection.

\section{Discussion}

This study did not take into account the protozoan although these organisms also form an important part of intestinal pathogens observed in fecal matter that is assessed in hospital laboratories in Chad. In our sample, there is a predominance of boys' contribution compared to the findings of several similar works in Africa and in the world (Zakai, 2004; Ostan, 2005; Raso, 2005; El Kettani, 2006 and Balcioglu, 2007). Age interval in our sample are 6 and 17 years, while in several studies carried out the world, they are 4 and 15 years (Kassi et al., 2008; El-Kettani, 2006; Stephane et al., 2004). This age difference can be explained by the delay in the enrollment of Chadian children in primary school (Salé Hagam, 2012).

Our survey revealed that $57.1 \%$ of children, that is about one child over two, were infested with at least one intestinal helminths species (Table 3). This value seems to be low because we did not use a specific method for the detection of Enterobius vermicularis, a parasite which is fairly common in children due to its peculiar life cycle (Adou-Brin et al., 2001). Local conditions and logistical constraints did not allow us to implement other techniques. Nevertheless, both methods used have the advantage of being simple, rapid, and inexpensive, and are suited for low-income countries (OMS, 1983; Tchuem Tchuenté, 2012). The prevalence rate of $57.1 \%$ corroborates those already found: $57.7 \%$ in N'Djamena by Kostoingue et al. (2002), $51 \%$ also in N'Djamena by Hamit et al. (2008), $56 \%$ in other tropical regions as in Gondar ( Ethiopia) by Worku et al. (2009), 54.7\% in the Delta state (Nigeria) by Egwunyenga et al. (2005), 60\% in the region of Lake Chad by Bechir et al. (2011), and 60\% in Makenene (Cameroon) by Tchuem Tchuenté et al. (2001). Our result does not tie with those of: Tchuem Tchuenté et al. (2003) who reported $90.3 \%$ in Loum (Cameroon), Nkengazong et al. (2010) in the South West region (Cameroon) with $42 \%$ and Brooker et al. (2002a) in Mayo Kebbi (Chad) with 37.5\%. The level of infection in this work still shows that intestinal helminths infections remain a public health problem in Chad.

The rate of infection was higher in boys than in girls (Table 3). This observation has been reported by several authors such as: Kassi et al. (1989) in Aboisso, Menan et al. (1997) in Abidjan, Adou-Brin (2001) in Toumodi and Stephane et al. (2004) in Agboville (Ivory Coast), Tchuem Tchuenté et al. (2012) in the Center, East and West regions of Cameroon. However, Agbolade et al. (2004) in southwestern Nigeria, OMS (2005) in Cape Verde, Hamit et al. (2008) in N'Djamena (Chad) and Kassi et al. (2008) in Divo (Ivory Coast), found no difference in infection between both sexes. This difference in prevalence rates, which only concerned $A$. 
lumbricoides, Ankylostoma sp., S. stercoralis and T. saginata (Table 5), can be explained by the fact that in Chad, the traditional education of girls is also different from that of boys. For example, during the days of rest, girls must stay at home to help their mothers with some household duties, while boys engage themselves in games and feed out of the homes. During these leisure activities, the risks of parasitic infections are higher (Hamit et al., 2008). Besides, this risk of contamination from street food had been highlighted by certain authors (Tidjani $e t$ al., 2006; Barro et al., 2007). Eight species of helminth were diagnosed during our investigation: four nematoda (A. lumbricoides, T. trichiura, hookworms and S. stercoralis), three cestoda (H. nana, T. solium and T. saginata) and a trematoda (S. mansoni). In a similar analysis conducted in southwest region of Cameroon, Nkengazong et al. (2010) identified the same four nematoda and showed prevalence rates higher in females than in males. This difference seems mainly due to the technical analysis of fecal matter collected. In addition to the method used by Nkengazong et al. (2010) the Kato, the formalin/ether method of concentration was included in the present study. Among the identified species, three are blood sucking (hookworm, T. trichiura and S. mansoni). This profile includes a risk of iron deficiency which provokes anemia that has been reported to have a negative impact on children academic performance and growth (Drake et al., 2000; Dreyfuss et al., 2000; Stephenson et al., 2000; Hall et al., 2001; WHO, 2002; Hotez et al, 2004; OMS, 2004; Tchuem Tchuenté et al., 2012). The presence in this study of transcutaneous-acquired helminthes (S. mansoni and hookworm) demonstrates a lack of environmental sanitation and an unprotected contact with the milieu.

This research study showed that intestinal helminthiasis in primary school pupils in Chad are mainly due to A. lumbricoides, H. nana, hookworm and S. stercoralis (Table 5). A similar finding had been published for the first two species by Brooker et al. (2000) in Cameroon, Saathoff et al. (2005) in South Africa, Goodman et al. (2007) in Zanzibar, Hamit et al. (2008) in Chad, and Zephania et al. (2010) in Cameroon. Recently, Bechir et al. (2011) demonstrated the prevalence of hookworm in Chad. The higher rate of ascaridiasis (33.7\%) in the present study confirms that this parasitosis is one of the most common in the world among geohelminthiases (Tchuem Tchuente et al., 2001 \& 2012; Montresor et al., 2002; Miguel \& Kremer, 2002, Ajeagah et al., 2013). However, trichuriasis is the first helminthiasis in some tropical areas; this is the case in Toumodi (Adou-Brin et al., 2001.) and Agboville respectively in the northen and southern part of Ivory Coast (Stephane et al., 2004), in the South-western (Nkengazong et al., 2010) and in the coastal region (Sumo, 2012) of Cameroon. Tchuem Tchuente et al. (2012) also found that A. lumbricoides and T. Trichuria are the most common helminthes in Cameroon. Regarding the trematode $S$. mansoni, the short duration and the fickleness of egg migration into blood capillaries could explain its low prevalence $(3.4 \%)$ obtained in this study. Hence, prevalence could be considered underestimated as some infected children did not have its eggs in their feces (Golvan, 1983; Theron et al., 1992). However, the interest of our study was first to identify the parasite species among school children.

Among the helminthes diagnosed, only two were found in the sudanian zone (Table 6), namely T. solium and S. mansoni. Apart from H. nana and T. saginata, the prevalences of all species appeared higher in the cities of the sudanian zone than in the sahelian zone (Table 6). Indeed, 
the sudanian zone is a wet and rainy forest region which is suitable for the dissemination of eggs (Brooker et al., 2002b; Savioli et al., 2002; Tchuem Tchuenté, 2003 \& 2011). Bokoro city, though found in the sahelian zone, also presented high infection rate with A. lumbricoides, $H$. nana and T. saginata (Table 6). This can be explained by the fact that in Bokoro, the schools visited lack toilets and a supply of pine-borne water; the low infection rate (19.8\%) observed in Abeche Catholic Associated Sisters School (Table 4) can be attributed to the presence of toilets and a water closet system with the presence of a sink to wash hands after the usage of the toilets. No other school among those visited is equipped with sanitation facilities, not even common water supply, although the center A school in Bongor is one of the oldest in the Central Africa region (Salé Hagam, 2012). Yet, health facilities in schools have been reported to reduce parasitic infections (Egwunyenga et al., 2005).

The parasite species diversity was higher in the age group "10-14" years. This result is similar to those of Kassi et al. (2008) in Divo (Ivory Coast) for the age range of 8-9 years and Stephane et al. (2004) in Agboville (Ivory Coast) for age range of "12-15" years. Similarly, Agbolade (2007) in a related study in Southwestern Nigeria reported a significant infection rate from 6 to 12 years old. Our result differs from that of Tchuem Tchuenté et al. (2012) in the Central, Eastern and Western Cameroon, who found parasite prevalence higher in the age group $\leq 9$ years, Nkengazong et al. (2010) in South West Cameroon with high infection in the class "1-5" age old, and Sumo (2012) in the Central region of Cameroon with the prevalence rate higher in the age group $>15$ years.

In the Chadian school context, parasitism seems to be directly related to lack of water and sanitation facilities. This infrastructural deficit does not facilitate high rules of hygiene in the community. This observation was also made in Cape Verde (OMS, 2005). The high prevalence rate assessed in our study is also associated to the source of water supply or storage of water. A low rate of children infected is seen in those with potable water supply (SNE) at home (Table 9). In Chad, the water storage is generally done in local clay pots called "canaries". This method and the poor maintenance of these containers increase chances of the infection rates. In our study, $0.5 \%$ of the children surveyed reported washing hands with soap before eating but most of them $(60 \%)$ hosted parasites; this result is explained by the fact that hands are washed in the same container, then wiped with the same towel (Hamit et al., 2008). Similarly, wearing closed shoes and having no pets in the house reduced the infection rates compared to wearing opened shoes (Table 9); several authors (Steinmann et al., 2000; Traub et al., 2004; Corrales et al., 2006) also reported that living in close proximity with pets increases the prevalence rate of intestinal parasites.

Monoparasitism was found in 290 pupils (28.9\% of the sample); quite the same percentage of polyparasitism was observed in 282 children who represent $28.14 \%$ of the sample. This proportion is lower than $76.7 \%$ recorded by Dancesco et al. (2005) in Ivory Coast but higher than $10.19 \%$ as indicated by Tchuem Tchuenté et al. (2012) in Cameroon. Three types of polyparasitism (by 2 to 4 species) were identified (Table 8) in contrast to Menan et al. (1997) in Ivory Coast, Buchy (2003) in Madagascar and Nkengazong et al. (2010) in Cameroon who reported the coexistence of 5, 8 and 3 species respectively. In our study, A. lumbricoides is the species mostly involved in parasitic associations and may thus be primarily responsible for 
malnutrition in school children.

Out of 121 pupils (12.1\% of the sample population), H. nana was associated with 1 to 4 other geohelminthes (A. lumbricoides, hookworm, S. stercoralis, T. trichiura). Except T. trichiura whose adults live in the coeco-appendicular mucosa (ANOFEL, 2010), the other three species mentioned are found in the adult stage hooked to the intestinal mucosa (small intestine). This parasitic biodiversity suggests that the infection process probably occurs simultaneously.

No case of simultaneous parasitism by the tapeworms T. saginata and T solium was observed; this confirms the name solitary worms given to these species (Golvan, 1983; ANOFEL, 2010). T. solium was only found to be associated to A. lumbricoides in one child; T. saginata coexisted with the same nematode and/or T. trichiura and S. stercoralis in 24 children. As for T. trichiura, 21 pupils harbored it with each of the other parasite species, except $T$. solium. This observation suggests either the absence of competitive interactions between the soil-transmitted helminthes identified, or that their parasitic loads are relatively low. This scientific study that took place in the seven most prominent towns of Chad, was carried out for a period of 12 months which is a complete ecological cycle. The findings of these researches will go a long way to attract the public power on the sanitary impact of the intestinal helminthiasis on school children. At our level, we used Albendazole (Zentel) to take care of all children infested at the unique dose of $400 \mathrm{mg} / \mathrm{infected}$ child. The food potentialities of Chadian children are basically made of cereal which is prepared in one form or the other, making it difficult to subdivide the samples into different nutritional status. The local conditions and the logistical constraints didn't permit us, to study the efficiency of the treatment and the dynamism of reinfestation of the helminths, even though a technical survey in this direction is planned for 2014.

\section{Conclusion}

The present study proofs that intestinal helminths are prominent among primary school children in Chad. A. lumbricoides and H. nana are higher in the two first places respectively among the helminths diagnosed in the two ecological zones. The overall prevalence of intestinal helminths in the Sudanian zone is higher than those obtained in the Sahelian region where worm biodiversity in the Sudanian zone is much higher with 8 parasites identified as opposed to 6 parasites in the Sahelian zone. School children in the age range of "10-14" are more often infected. The profile of the above-described intestinal parasitosis suggests that the success in the fight against these diseases passes through sanitation efforts of schools, health education of parents, improvement of personal hygiene, maintenance of transport and storage of water containers, regular and sustainable deparasitation in schools and in the general population. It is also important to ensure the hygiene and health conditions of pets. All these findings show that despite the significant increase in the standard of living and the current consolidation efforts in cities such as N'Djamena, Abeche and Bongor, intestinal helminth infections remain a major public health problem in Chadian primary schools. Considering the overall prevalence in this study $(57.1 \%)$ and given the prevalence of over $60 \%$ in some cities, it is necessary to carry out a systematic deworming of the population at least once every three months. The medical authority in Chad has everything to gain by adopting a national program to fight against the spread of intestinal-helminths. 


\section{Acknowledgement}

We thank Dr Ajeagah Gideon of the University of Yaounde 1; for proofreading the manuscripts.

\section{References}

Adibord, M. Y. (1998). Sites urbains, les problèmes des inondations à N’Djamena. Mémoire de Diplôme d'Etudes Approfondies (DEA) de géographie. Université de Provence Aix- Marseille, 120p.

Adou-Brin, D., Kouassi, M., Ouhon, \& J. et Assoumou, A. (2001). Prévalence globale des parasitoses à transmission orale chez les enfants à Toumodi (Côte d'Ivoire). Médecine d'Afrique Noire, 48(10), 395-398.

Agbolade, O., Agu, N., Adesanya, O., \& Odejayi, A. (2007). Intestinal helminthiasis and schistosomiasis among school children in an urban center and some rural communities in southwest Nigeria. Korean journal of parasitology, 45(3), 233-8. http://dx.doi.org/10.3347/kjp.2007.45.3.233

Agbolade, O. M., Akinboye, D. O., \& Awolaja, A. (2004). Intestinal helminthiasis and urinary schistosomiasis in some villages of Ijebu North, Ogun State, Nigeria. African Journal of Biotechnology, 3(3), 206 -209.

Ajeagah, G., Wouafo, M., Ezenguele, G., Nzukam, J. (2013). Presence of gastrointestinal parasites in an urban region yaounde, Cameroon. comparative parasitology, 80(2), 279-283.

ANOFEL (2010). Parasitoses et mycoses des régions tempérées et tropicales. Association française des enseignants de parasitologie et mycologie médicales (ANOFEL). $2^{\mathrm{e}}$ Edition, Elsevier Masson, 362p.

Balcioglu, I. C., Kurt, O., Limoncu, M. E., Dinç, G., Gümüş, M., Kilimcioglu, A. A., Kayrane, E., \& Ozbilgi. (2007). A Rural life, lower socioeconomic status and parasitic infections. Parasitology International, 56(2), 129-33. http://dx.doi.org/10.1016/j.parint.2007.01.005

Barro, N., Razack, B. A., Yollande, I., Savadogo, A., Ouattara, C. A. T., Nikiema, P. A., De Souza, C., \& Traoré, A. S. (2007). Street vended foods improvement: contamination mechanisms and application of food safety objective strategy: critical review. Pakistan Journal of Nutrition, 6, 1-10. http://dx.doi.org/10.3923/pjn.2007.1.10

Bechir, M., Schelling, E., Hamit, M. A., Tanner, M., \& Zinsstag, J. (2011). Parasitic Infections, Anemia and Malnutrition Among Rural Settled and Mobile Pastoralist Mothers and Their Children in Chad. EcoHealth. http://dx.doi.org/10.1007/s10393-011-0727-5

Brooker, S., Hay, S. I., \& Bundy, D. A. P. (2002a). Tools from ecology: useful for evaluating infection risk models? Trends in Parasitology, 18, 70-74. http://dx.doi.org/10.1016/S1471-4922(01)02223-1.

Brooker, S., Beasley, M., Ndinaromtan, M., Madjiouroum, E., Baboguel, M., Djenguinabe, E., Hay, S., \& Bundy, D (2002b). Use of remote sensing and a geographical information system in 
a national helminth control programme in Chad. Bulletin of the World Health Organization, 80, 783-789.

Brooker, S., Donnely, C. A., \& Guyatt, H. L. (2000). Estimating the number of helminthic infections in the republic of Cameroon from data on infection prevalence in school children. Bulletin of the World Health Organization, 78, 1456-1465.

Buchy, P. (2003). Les parasitoses digestives dans la région de Mahajanga, côte Ouest de Madagascar. Bulletin de la Société de pathologie exotique, 96(1), 41-45.

Bundy, D. A. P., Murray, C. J. L., \& Lopez, A. D. (1997). Intestinal nematode infections, in Health Priorities and Burden of Disease Analysis: Methods and Applications from Global, National and Sub-national Studies. Bulletin of the World Health Organization, 99, 1542-58.

CNAR. (1998). Centre national d'appui à la Recherche, Ministère de l'Enseignement Supérieur et de la Recherche Scientifique, Rapport: les zones écologiques du Tchad, 39p.

Corrales, L. F., Izurieta, R., \& Moe, C. L. (2006). Association between intestinal parasitic infections and type of sanitation system in rural El Salvador. Tropical Medicine and International Health, 11, 1821-1831. http://dx.doi.org/10.1111/j.1365-3156.2006.01737.x

Dancesco, P., Jérôme, Abeu, Akakpo, C., Iamandi, I., Kacou, E., Quenou ,F. et Keusse-Assi, J. (2005). Les parasitoses intestinales dans un village de Côte d'Ivoire: essai de mise en place d'une stratégie de lutte et de prévention. Cahiers Santé, 15(4), 5-10.

DREM. (2013). Ministère de l'Environnement. Division de climatologie. Rapport de février 2013 de la Direction des Ressources en Eaux et de la Météorologie du Tchad, 23p.

Drake, L. J, Jukes, M. C. H., Sternberg, R. J., \& Bundy, D. A. P. (2000). Geohelminth infections (Ascariasis, Trichuriasis and Hookworm), cognitive and developmental impacts. Seminars in Pediatric Infectious Diseases, 11, 245-251. http://dx.doi.org/10.1053/spid.2000.9638

Dreyfuss, M. L. J., Stoltzfus, R., Shrestha, J. B., Pradhan, E. K., Leclerq, S. C., Khatry, S. K., Shresrha, S. R., Katz, J., Albonico, M., \& West, K. P. J. R. (2000). Hookworms, malaria and vitamin A deficiency contribute to anemia and iron deficiency among pregnant women in the plains of Nepal. Journal of Nutrition, 130, 2527-2536.

Edwin, J. (2004). Schistosomiase et géohelminthiases: prévention et lutte. Rapport d'un comité d'expert de l'OMS. Genève, Organisation Mondiale de la Santé, Série de rapports techniques, 912, 142-158.

Egwunyenga, O., \& y Ataikiru, and Palmer D. (2005). Soil-transmitted helminthiasis among school age children in Ethiope East Local Government Area, Delta State, Nigeria. African Journal of Biotechnology, 4(9), 238-241.

El-Kettani, \& Azzouzi, EL M. (2006). Prevalence of helminthes in a rural population using wastewater for agricultural purposes at Settat (Morocco). Santé, 16(4), 245-51. 
Fleiss, J. L. (1981). Statistical methods for rates and proportions. New-York: John Wiley and Sons: $321 \mathrm{p}$.

Golvan, Y. J. (1983). Eléments de parasitologie médicale. $4^{\text {éme }}$ édition. Paris: Flammarion-médecine science: $571 \mathrm{p}$.

Goodman, D., Haji, H. J., \& Bickle, Q. D. (2007). A comparison of methods for detecting the eggs of Ascaris, Trichuris, and hookworm in infant stool, and the epidemiology of infection in Zanzibari infants. American Journal of Tropical Medicine and Hygiene, 76, 725-731.

Hall, A., Bobrow, E., Brooker ,S., Jukes, M., Nokes, K., Lambo, J., Guyatt, H., Bundy, D., Adjei ,S., Wen, S. T., Satoto, Subagio, H., Rafiluddin, M. Z., Miguel, T., Moulin, S., Johnson, J. G., Mukaka, M., Roschnik, N., Sacko, A. M., Zacher, A., Mahumane, B., Kihamia, C., Mwanri, L., Tatala, S., Lwambo, N., Siza J., Khanh, L. N., Bkhoi, H. H., \& Toan, N. D. (2001). Anaemia in schoolchildren in eight countries in Africa and Asia. Public Health Nutrition, 44(8), 67-71.

Hamit, M. A., Tidjani, M. T., \& Bilong Bilong, C. F. (2008). Recent data on the prevalence of intestinal parasites in N'Djamena, Chad Republic. African Journal of Environmental Science and Technology, 2(12), 407-411.

Hotez, P. J., Brooker, S., Bethony, J. M., Bottazzi, M. E., Loukas, A., \& Xiao, S. (2004). Current concepts: Hookworm infection. New England Journal of Medicine, 351, 799-07. http://dx.doi.org/10.1056/NEJMra032492

INSEED/RGPH2 (2010). Ministère de la coopération du Tchad. Institut Nationale de la Statistique des Etudes Economiques et Démographique/ Rapport du $2^{\text {ème }}$ recensement général de la population et de l'habitat 2010,235p.

Kassi, E. A. (1989). Contribution à l'étude des helminthiases intestinales et urinaires en Côte d'Ivoire. Résultats obtenus en milieu scolaire dans cinq localités de la région d'Aboisso. Thèse de Doctorat en Médecine. Université d'Abidjan (Côte d'Ivoire), 155p.

Kassi, F., Menan, E. I. H., Yavo, W., Oga, S. S. A., Djohan, V., Vanga, H., Barro, P. C. K., Adjetey, \& T. A. K. et Kone, M. (2008). Helminthoses intestinales chez les enfants d'âge scolaire de la zone rurale et urbaine de Divo (Côte d'ivoire). Cahier Santé Publique, 7(1), 51-60.

Katz, N., Chaves, A., \& Pellegrino, J. (1972). A simple device for quantitative stool thick-smear technique in Schistosomiasis mansoni. Revista do Instituto de Medicina Tropical de Sao Paulo, 14, 397-400.

Kostoingue, B., Tidjani, M. T., Mbaideji, \& F. et Hamit, M.A. (2002). Prévalence des parasitoses intestinales chez les enfants de 0 à 5 ans dans la ville de N'Djaména. Médecine d'Afrique noire, 49(12), 533-536.

Menan, E. I. H., Nebavi, N. G. F, Adjetey, T. A. K, Assavo, N. N., Kiki-Barro, \& P. C. et Kone, M. (1997). Profil des helminthiases intestinales chez les enfants d'âge scolaire dans la ville d'Abidjan. Médecine d'Afrique Noire, 90(1), 59-63. 
Miguel, E., \& Kremer, M. (2002). Worms: Identifying Impacts on Health and Eradication in the Presence of Treatment Externalities. Journal of parasitology, 14(5), 279-290.

Montresor, A, Crompton, D. W. T, \& Savioli, L. (2002). Helminth control in school-age children: a guide for managers of control programs. World Health Organization Technical Report Series. Document WHO/CDS/CPC/SIP/99, 107p.

NKengazong, L., Njiokou, F., Wandji, S., Teukeng, F., Enyong, P., \& Asonganyi, P. (2010). Prevalence of soil transmitted helminths and impact of Albendazole on parasitic indices in Kotto Barombi and Marumba II villages ( South-West Cameroon). African Journal of Environmental Science and Technology, 4(3), 115-121.

Odongo-Aginya, E. I, Kabatereine, N., \& Ludwig, S. (2007). Substitution of malachite green with nigrosin-eosin yellow stain in the Kato-Katz method: microscopical appearance of the helminth eggs. African Health Science, 7, 33-36.

OMS (1983). Cellophane fecal thick smear examination technique for diagnosis of intestinal schistosomiasis and gastrointestinal helminthiasis infections. WHO/CDS/SIP/82, 32p.

OMS (1993). Infestation et anémie ankylostomienne. Series de rapports techniques. 876: 57p.

OMS (2001). Schistosomiase et helminthiases d'origine tellurique. Séries de rapports techniques, WHO/CDS/SIP/2000, 32p.

OMS (2004). Lutte contre les helminthiases chez les enfants d'âge scolaire: guide à l'intention des responsables des programmes de lutte. WHO/CDS/CPC/SIP/2003, 189p.

OMS (2005), enquête sur les parasitoses intestinales dans les écoles et les jardins d'enfants. Séries de rapports techniques: OMS, CAP-VERT (45), 55p.

OMS (2010), La schistosomiase au Tchad. Séries de rapports techniques : OMS TCHAD, 20p.

Ostan, I., Kilmcioglu, A. A., Girginkardesler, N., Ozyurt, B. C., Limoncu, M. E., \& Okuz. (2005). Health inequities: lower socio-economic conditions and higher incidences of intestinal parasites. Niger Postgrad, Medical Journal, 12(1), 23-35.

Perez, E., Gazin, P. Furtado, A., Miranda, P., Marques, N. M., \& Silva, M. R. (2000). Parasitoses intestinales et schistosomose en milieu urbain en région littorale et en région semi-aride du Nord-Est du Brésil. Bulletin-Santé, 10(2), 127-9.

Raso, G., Utzinger, J, Silué, K. D., Ouattara, M., Yapi, A., Toty, A., Mattys, B., Vounatsou P., Tanner M., \& N'goran, E. K. (2005). Disparities in parasitic infections, perceived ill health and access to health care among poorer and less poor school children of rural Côte d'Ivoire. Tropical Medecine and Internatinal Health, 10(1), 42-57. http://dx.doi.org/10.1111/j.1365-3156.2004.01352.x

Saathoff, E., Olsen, A., \& Kvalsvig, J. D. (2005). Ecological covariates of Ascaris lumbricoides infection in school children from rural Kwa-Zulu-Natal, South Africa. Tropical Medecine and International Health, 10, 412-422. http://dx.doi.org/10.1111/j.1365-3156.2005.01406.x 
Salé Hagam. (2012). Développement de l'éducation en Afrique subsaharienne (exemple du Tchad). Edition, Harmattan, 347p.

Savioli, L., Stansfield, S., Bundy, D. A. P., Mitchell, A., Bhatia, R., Engels, D., Montressor, A., Neira, M., \& Shein, A. M. (2002). Schistosomiasis and soil transmitted helminth infections: Forging control efforts. Transactions of the Royal Society of Tropical Medicine and Hygiene, 96, 577-579. http://dx.doi.org/10.1016/S0035-9203(02)90316-0

Spiegel, A., Moulia, P., Daumerie, D., Merlin, M., \& Baudon, D. (1989). Le sondage en grappes. Type OMS. Méthode pratique en épidémiologie descriptive. Médecine Afrique Noire, 36(10), 740-743.

Steinmann, P., Zhou, X-N., \& Li, Y-L. (2007). Helminth infections and risk factor analysis among residents in Eryuan county, Yunnan province, China. Acta Tropica, 104, 38-51. http://dx.doi.org/10.1016/j.actatropica.2007.07.003

Stephane, S. Oga Agbaya, Yavo, W., Ebi Menan, E. I. H., M'boya, A. A., Kouadio, L. P. et Moussa Koné. (2004). Helminthiases intestinales chez les enfants d'âge scolaire : résultats préliminaires d'une étude prospective à Agboville dans le sud de la Côte d'Ivoire. Cahiers d'études et de recherches francophones / Santé, 14(3), 143-7.

Stephenson, L. S., Latham, M. C., \& Ottesen, E. A. (2000). Malnutrition and parasitic helminth infections. Parasitology, 56(121), 23-38. http://dx.doi.org/10.1017/S0031182000006491

Sumo, L. (2012). Schistosomiase et geohelminthiases: efficacité du traitement et dynamique de réinfestation. Thèse de Doctorat/Ph.D, Université de Yaoundé I: 126 p.

Tchuem Tchuenté, L. A., Sougathe V. R., \& Vercruysse J. (2001). La bilharziose et les geohelminthes dans l'arrondissement de Makénéné. Province du centre, Cameroun. Bulletin de liaison et de documentation de l'OCEAC, 34(2), 19-22.

Tchuem Tchuenté, L. A, Behnke, J. M., Gilbert, F. S., Sougathe, V. R., \& Vercruysse, J. (2003). Polyparasitism with Shistosoma haematobium and soil-transmitted helminth infestions among children in Loum, Cameroon. Tropical medicine and international health, 8(11), 975-986. http://dx.doi.org/10.1046/j.1360-2276.2003.01120.x

Tchuem Tchuenté, L. A. (2011). Control of soil-transmitted helminths in sub-Saharan Africa: Diagnosis, drug efficacy concerns and challenges. Acta Tropica, 120(1), 4-11. http://dx.doi.org/10.1016/j.actatropica.2010.07.001

Tchuem Tchuenté, L.A, Romuald, I. K. N., Sumo, L., Ngassam, P., Calvine, D. N., Deguy, D. L. N., Dankoni, E., Kenfack, C. M, Feussom, N. G., Akame, J., Tarini, A., Yaobi Zhang, \& Angwafo, F. F. III, (2012). Mapping of Schistosomiasis and Soil-Transmitted Helminthiasis in the Regions of Centre, East and West Cameroon. PLoS Neglected Tropical Diseases, 6(3), e1553.

Théron, A., Mone, H., \& Gerard, C. (1992), spatial and energy compromise between host and parasite: the Biomphalaria glabrata - Shistosoma mansoni system. International journal for Parasitology, 22, 91-94. http://dx.doi.org/10.1016/0020-7519(92)90084-X 


\section{Macrothink}

Tidjani, A., Brahim, B. O., Ameyapoh, B., Soncy, M., Anani, \& T. et De Souza, C. (2006). Appréciation de la qualité hygiénique des grillades de bœufs vendues à Lomé (Togo). Annale Universitaire. N'Djamena, 6, 82-88.

Traub, R. J., Robertson I. D., \& Irwin, P. (2004). The prevalence, intensities and risk factors associated with geohelminth infection in teagrowing communities of Assam, India. Tropical Medecine and Health, International 9, 688-701. http://dx.doi.org/10.1111/j.1365-3156.2004.01252.x

Unicef (2007). Focosing Resources on Effective School Health. www.unesco.org Education -Helminthes et hygiene, $54 \mathrm{p}$.

Van der Werf, M. J. (2003). Quantification of clinical morbidity associated with schistosome infection in sub-Saharan Africa, Acta Tropica, 86, 125-39. http://dx.doi.org/10.1016/S0001-706X(03)00029-9

WHO (2002). Prevention and control of schistosomiasis and soil-transmitted helminthiasis: World Health Organization, Geneva, Switzerland. Technical Report Series (912), 267p.

Worku, N., Erko, B., Torben, W., Belay, M., Kasssu, A., Fetene, T., \& Huruy, K. (2009). Malnutrition and intestinal parasitic infections in school children of Gondar, North West Ethiopia. Ethiopian Medical Journal, 47, 9-16.

Zakai, H. A. ( 2004). Intestinal parasitic infections among primary school children in Jeddah, Saudi. Intestinal helminthiasis in school children in Haiti in 2002 Arabia. Journal of the Egyptian Society of Parasitology, 34(3), 783-790.

Zephania, Nji Fogwe, \& Fombutio Christopher Ndifor (2010). Tropical City Milieux and Disease Infection: The Case of Douala, Cameroon. Journal of Human Ecology, 30(2), 123-130.

\section{Copyright Disclaimer}

Copyright reserved by the author(s).

This article is an open-access article distributed under the terms and conditions of the Creative Commons Attribution license (http://creativecommons.org/licenses/by/3.0/). 